\title{
An intimate sort of literature
}

Previously published at www.cmaj.ca

Bodies \& Barriers: Dramas of Dis-Ease Angela Belli, Editor

Kent State University Press; 2008.

I n Bodies \& Barriers: Dramas of Dis-Ease, editor Angela Belli guides the reader through seven plays that explore or invoke medical issues. She shares a formidable knowledge of dramatic literature, not only addressing the featured works, but also describing pertinent connections to other plays and playwrights ranging from Sophocles to Henrik Ibsen.

Belli wisely insists that the reader pay attention to the structure of each play as well as its content. In her excellent introduction to $W ; t$, Belli highlights specific moments in the play that interrogate the specialized language of medicine and the problems that can arise from professional detachment. She also attends to playwright Margaret Edson's deft use of theatrical technique, as when monologues delivered

\section{Belli has created a collection that is accessible to readers interested in theatre.}

simultaneously by a doctor and a patient emphasize the confusion and frustration that can result from different perspectives on the same event.

By offering seven plays that are well known and highly regarded (eight Tony Awards and a Pulitzer Prize among them), Belli creates a collection accessible to readers interested in - but not $\stackrel{m}{7}$ necessarily scholars of - the theatre.

However, this ease of use comes at the price of diversity: All of the authors are American or British and five of the seven are white men. Belli clearly realizes the importance of the sociocultural identities of the playwrights

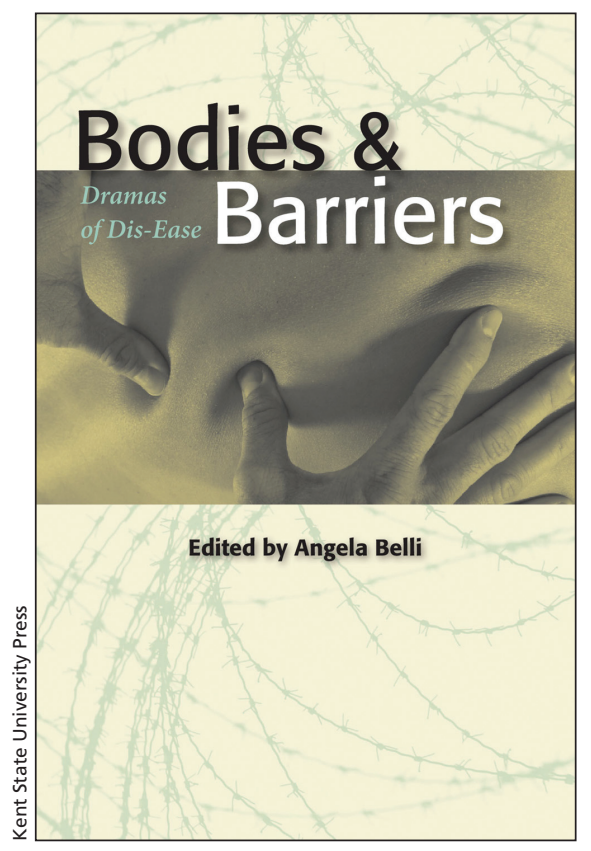

and the characters they create. She describes Cheryl L. West's play Before It Hits Home as a "culturally sensitive work" for its rare portrayal of an African-American family in the midst of a health crisis. But in the same intro-

duction, Belli makes the disputable claim that West's play "transcends race and culture."

Perhaps even more strikingly narrow is the time period represented by these plays: four were written in the late 1970s and none is more recent than 1993. AIDS is no longer the automatic death sentence that it is in Before It Hits Home (1998). Options for living with a disability have changed greatly since Brian Clark wrote Whose Life Is It Anyway? (1978).

This is not to say that older plays are obsolete in discussions of health and medicine. The neglect of an elder in the absurd beach scene that is Edward Albee's 1959 play The Sandbox still rings true 50 years later. In Wings, Arthur Kopit portrays recovery from a stroke in what easily could be either 1978 or 2009 or any year between: An accurate sense of time is one of the mental faculties lost by the protagonist. In her helpful introduction to Michael Cristofer's The Shadow Box, Belli notes that hospice care was a fledgling concept when this play was first produced in 1977, giving historical context to the end-of-life quandaries faced by Cristofer's fictional characters.

Taken as a limited selection rather than as a representative collection, Bodies \& Barriers is rich with possibilities for sparking discussions of health and medicine. Belli introduces The Elephant Man (1979), by Bernard Pomerance, with a statement that it "recreates the real-life experience of John Merrick." Merrick's first name was, in fact, Joseph, and this play is not meant to be a documentary. The very inventiveness with which Pomerance reimagines Merrick's life encourages the reader to imagine even further ways in which the themes of this story might resonate.

The study and practice of medicine depend on accumulation of knowledge in various settings, ranging from examination rooms to auditoriums. Each venue offers distinct advantages for learning from the experiences of individual patients and applying those lessons to future situations. In Bodies \& Barriers, Belli has chosen a literary genre especially apt for a medical context. Texts written for the stage are an intimate sort of literature, intended for live encounters with words and actions, ultimately concerned with real bodies.

\section{Gretchen Case PhD}

Thompson writing program fellow Duke University

Durham, USA 